\title{
Cardiac arrhythmias following the creation of an atrial septal defect in patients with transposition of the great arteries
}

\author{
R. J. MOENE, J.P. ROOS, and A. EYGELAAR \\ Departments of Paediatric Cardiology and Cardiology, Free University Hospital, Amsterdam, and the \\ Department of Thoracic Surgery, University Hospital, Groningen, The Netherlands
}

In 64 children with transposition of the great arteries who underwent a Blalock-Hanlon procedure, pre- and postoperative electrocardiograms were studied regarding the incidence and nature of rhythm disturbances. In another group of 19 patients with transposition of the great arteries, the atrial septal defect was created by a different surgical technique (fossa ovalis resection); this group was studied in the same way and the results were compared.

After the Blalock-Hanlon procedure seven patients developed arrhythmias including atrioventricular (A-V) dissociation, wandering pacemaker, bradycardia, atrial flutter, supraventricular tachycardia, supraventricular premature beats, and ectopic atrial rhythm. After fossa ovalis resection rhythm disturbances were present in three patients.

Despite their relatively high incidence it seems unlikely that arrhythmias are a major factor contributing to death irrespective of the technique used; some arrhythmias are transient and serious disturbances of long duration are rare.

In complete transposition of the great arteries the systemic and pulmonary circulations function in parallel and are independent of each other. Postnatal survival of babies with this congenital malformation is possible only in the presence of adequate intracardiac shunting (atrial septal defect, ventricular septal defect) and/or extracardiac shunting (persistent ductus arteriosus and pulmonary collateral circulation) (Paul, Van Praagh, and Van Praagh, 1968). Quite often, however, the communication between the two circulations is inadequate, resulting in deep cyanosis and congestive heart failure. The creation or enlargement of an atrial septal defect in order to improve the bidirectional shunting of blood can be accomplished by the intracardiac balloon-catheter technique (Rashkind and Miller, 1966) or by a surgical procedure. Hamilton et al. (1968) reported an unexpected number of arrhythmias and conduction disturbances following the creation of an atrial septal defect by the BlalockHanlon technique (Blalock and Hanlon, 1950). The purpose of this study is to evaluate the relative frequency and nature of cardiac arrhythmias in our series of patients who underwent a BlalockHanlon operation in comparison with those who had an open surgical procedure (fossa ovalis resec- tion) using temporary inflow occlusion (Homan van der Heide, Eygelaar, Dorlas, and Bossina, 1967 ; Litwin, Plauth, Jones, and Bernhard, 1971).

\section{PATIENTS AND METHODS}

Between 1958 and 1970, 91 Blalock-Hanlon operations were performed at Leyden University Hospital. Twenty-seven patients were excluded from this study because they died before a postoperative electrocardiogram could be taken; this study therefore comprises 64 patients. The ages of the patients at the time of operation ranged from 1 day to 10 years. Thirty-five patients received digoxin preoperatively; all were on maintenance digoxin postoperatively. Nineteen of 64 patients had had a balloon atrial septostomy some months or weeks previously but nevertheless operation was necessary because of increasing cyanosis after an initial improvement. Transposition of the great arteries was complicated by a ventricular septal defect in 21 patients and by a ventricular septal defect and a pulmonary stenosis in 10 patients. During the BlalockHanlon procedure a banding of the pulmonary artery was performed in 12 patients, a cavo-pulmonary anastomosis in four patients, and an ascending aortaright pulmonary artery shunt in one patient.

Resection of the fossa ovalis was performed in 34 patients at the University Hospital in Groningen 
between 1964 and $1970 ; 19$ patients could be included in this study since they had both pre- and postoperative electrocardiograms.

Of these 19 patients, a ventricular septal defect complicated the transposition in five cases; in four cases there was both a ventricular septal defect and a pulmonary stenosis; during the fossa ovalis resection one banding was performed, one Blalock shunt, one cavo-pulmonary shunt, and one ascending aorta to right pulmonary artery shunt. Seven of the 19 patients had had a balloon atrial septostomy previously. At the time of operation the patients were aged from 3 days to 4 years; 16 patients were on digoxin preoperatively and all were on maintenance digoxin postoperatively. All preoperative and postoperative electrocardiograms were studied for rhythm and conduction disturbances.

Electrocardiograms of the two groups of patients were taken at different times postoperatively; the time of the initial cardiogram ranged from one day to four weeks after operation. The follow-up period ranged from one day to six years and came to an end at the time of this study, or earlier if a total correction had been performed; follow-up ceased at death in four patients following fossa ovalis resection and in 18 patients following the BlalockHanlon procedure.

\section{RESULTS}

BLALOCK-HANLON PROCEDURE Before operation all 64 patients were in sinus rhythm; at different times after surgery seven patients showed rhythm

T A B L E I

RHYTHM DISTURBANCES FOLLOWING BLALOCKHANLON PROCEDURE (7 PATIENTS)

(Banding of the pulmonary artery was performed at the same time in patients 1,2 and 5.)

\begin{tabular}{|c|c|c|c|}
\hline Patient & Type of Disturbance & $\begin{array}{l}\text { Time } \\
\text { Post-op }\end{array}$ & Duration \\
\hline 1 & $\begin{array}{l}\text { (a) A-V dissociation } \\
\text { (sinus arrhythmia, } \\
\text { rate } 100 / \text { min; A-V } \\
\text { nodal rhythm, rate } \\
80 / \text { min) } \\
\text { (b) Wandering } \\
\text { pacemaker }\end{array}$ & $4 \frac{1}{2} \mathrm{yr}$ & $\begin{array}{l}\text { Total follow-up period } \\
\text { of } 4 \mathrm{yr}^{1}\end{array}$ \\
\hline 2 & Wandering pacemaker & 1 week & $\begin{array}{l}\text { Total follow-up period } \\
\text { of } 6 \mathrm{mth}^{1}\end{array}$ \\
\hline 3 & $\begin{array}{l}\text { (a) Atrial flutter } \\
\text { (b) Supraventricular } \\
\text { tachycardia }\end{array}$ & $\begin{array}{l}2 \mathrm{mth} \\
1 \mathrm{yr}\end{array}$ & $\begin{array}{l}8 \mathrm{mth} \\
\text { Total follow-up period } \\
\text { of } 4 \mathrm{yr}^{1}\end{array}$ \\
\hline 4 & $\begin{array}{l}\text { Supraventricular } \\
\text { tachycardia }\end{array}$ & 4 days & 2 days \\
\hline 5 & Ectopic atrial rhythm & $1 \mathrm{yr}$ & $\begin{array}{l}\text { Total follow-up period } \\
\text { of } 4 \mathrm{yr}^{1}\end{array}$ \\
\hline 6 & Ectopic atrial rhythm & $3 \mathrm{yr}$ & $\begin{array}{l}\text { Total follow-up period } \\
\text { of } 2 \mathrm{yr}^{2}\end{array}$ \\
\hline 7 & $\begin{array}{l}\text { Supraventricular } \\
\text { premature beats }\end{array}$ & $2 \mathrm{mth}$ & 3 weeks \\
\hline
\end{tabular}

1 Follow-up ended at time of this study

Follow-up ended at time of total correction disturbances (Table I). The disturbances included A-V dissociation, wandering pacemaker, bradycardia, atrial flutter, supraventricular tachycardia, supraventricular premature beats, and ectopic atrial rhythm.

Normal rhythm returned spontaneously in two of the seven patients after respectively two days and three weeks; in the remaining five patients, the disturbances were present during the total follow-up period; in three of these five patients a banding of the pulmonary artery had been performed simultaneously. The time of the first onset of the arrhythmias ranged from four days to four and a half years postoperatively. Each of two patients showed two different arrhythmias; in one patient $\mathrm{A}-\mathrm{V}$ dissociation was followed by a wandering pacemaker, and in a second patient atrial flutter was followed by supraventricular tachycardia (Fig. 1). One patient had a wandering pacemaker resulting in periods of bradycardia (Fig. 2). An ectopic atrial rhythm occurred in two patients (Fig. 3). Eleven patients showed a distinct lengthening of the P-wave for the first time one week to three years postoperatively; the maximal normal duration of $0.08 \mathrm{sec}$ (Nadas, 1963) was exceeded in four patients (Fig. 4).

FOSSA OVALIS RESECTION Preoperatively all 19 patients had a sinus rhythm; after operation three patients presented with arrhythmias (Table II). Complete heart block was present in one patient

T A B L E I I

RHYTHM DISTURBANCES FOLLOWING FOSSA OVALIS RESECTION (3 PATIENTS)

\begin{tabular}{|c|c|c|c|}
\hline Patient & Type of Disturbance & Time Post-op & Duration \\
\hline $\overrightarrow{1}$ & $\begin{array}{l}\text { Complete heart } \\
\text { block }\end{array}$ & $\begin{array}{l}\text { Immediate } \\
\text { (trauma by } \\
\text { suction cannula) }\end{array}$ & $\begin{array}{l}\text { Until death } 4 \\
\text { weeks post-op }\end{array}$ \\
\hline 2 & $\begin{array}{l}\text { A-V dissociation } \\
\text { (sinus arrhythmia, } \\
\text { rate } 110 / \mathrm{min} ; \mathrm{A}-\mathrm{V} \\
\text { nodal } \mathrm{rhythm} \text {, } \\
\text { rate } 100 / \mathrm{min} \text { ) }\end{array}$ & 2 weeks & $\begin{array}{l}\text { Control ECG two } \\
\text { years post-op: } \\
\text { sinus rhythm }\end{array}$ \\
\hline 3 & $\begin{array}{l}\text { Supraventricular } \\
\text { premature beats }\end{array}$ & 8 days & $\begin{array}{l}\text { Control ECG three } \\
\text { months post-op: } \\
\text { sinus rhythm }\end{array}$ \\
\hline
\end{tabular}

from immediately after the operation until his sudden death four weeks later (Fig. 5); during the operation the area of the coronary sinus was damaged by a suction cannula and this accident is thought to have caused heart block.

The two patients with supraventricular premature beats (Fig. 6) and A-V dissociation reverted spontaneously to sinus rhythm after respectively three months and two years. A widen- 


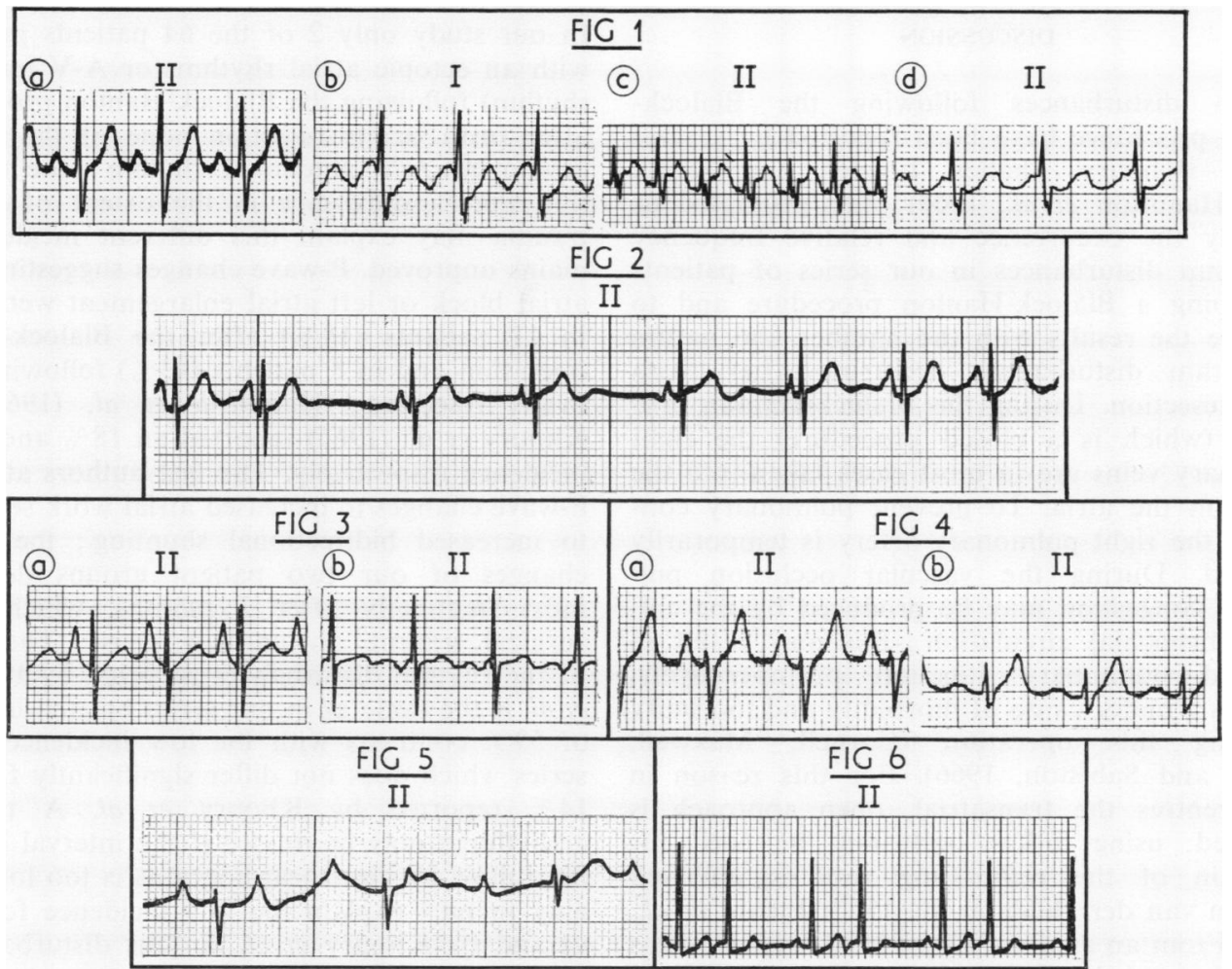

FIG. 1. Electrocardiograms (a) one week before the Blalock-Hanlon operation, (b) two months, (c) two years, and $(d)$ three years after surgery. (a) sinus rhythm; (b) atrial flutter; (c) supraventricular tachycardia with electrical alternans; (d) atrial tachycardia with 2:1 A-V conduction.

FIG. 2. Tracings taken one week after surgery (Blalock-Hanlon procedure and banding of the pulmonary artery) showing a wandering pacemaker.

FIG. 3. Tracings taken (a) one week before surgery (Blalock-Hanlon procedure and banding of the pulmonary artery) and (b) one year after surgery: (a) sinus rhythm, $P$ pulmonale; (b) ectopic atrial rhythm.

FIG. 4. Tracings taken (a) one week before surgery (Blalock-Hanlon procedure and cavopulmonary anastomosis) and (b) six months after surgery: (a) sinus rhythm, high peaked $P$-wave; (b) intra-atrial block or $\boldsymbol{P}$ mitrale.

FIG. 5. Complete heart block immediately after fossa ovalis resection. (During operation the A-V node was damaged by a suction cannula.)

FIG. 6. Premature beats of supraventricular origin eight days after fossa ovalis resection.

ing of the $\mathbf{P}$-wave over its previous preoperative form was present in eight patients; in four of these a duration of $008 \mathrm{sec}$ was exceeded. The rhythm disturbances after the creation of an atrial septal defect by the two different techniques are summarized in Table III.
T A B LE III

\begin{tabular}{c|c|c}
\hline Operation & No. of Patients & $\begin{array}{c}\text { No. with Rhythm } \\
\text { Disturbance }\end{array}$ \\
\hline $\begin{array}{l}\text { Fossa ovalis resection } \\
\text { Blalock-Hanlon procedure }\end{array}$ & $\begin{array}{c}19 \\
64\end{array}$ & 3 \\
\hline
\end{tabular}




\section{DISCUSSION}

Rhythm disturbances following the BlalockHanlon procedure have been reported by several authors (Khoury, Shaher, Fowler, and Keith, 1966 ; Hamilton et al., 1968) ; this prompted us to study the occurrence and relative frequency of rhythm disturbances in our series of patients undergoing a Blalock-Hanlon procedure and to compare the results with the number and nature of rhythm disturbances occurring after fossa ovalis resection. During the Blalock-Hanlon procedure (which is a closed procedure) the right pulmonary veins are in most cases taken into the clamp on the atria. To prevent pulmonary congestion the right pulmonary artery is temporarily occluded. During the vascular occlusion pulmonary congestion may be produced by the collateral bronchial circulation; this may result in impaired pulmonary function postoperatively, which is a major cause of morbidity and mortality following this operation (Cornell, Maxwell, Haller, and Sabiston, 1966). For this reason in some centres the transatrial, open approach is preferred; using inflow occlusion the need for occlusion of the right lung root is obviated (Homan van der Heide et al., 1967; Litwin et al., 1971). From an anatomical point of view it seems likely that, of the three internodal tracts (James, 1963), only the middle internodal tract is subject to trauma or interruption during fossa ovalis resection; during the Blalock-Hanlon procedure, however, a clamp is applied over the crista terminalis of the right atrium and may cause injury to the posterior internodal tract while resection of the posterior portion of the atrial septum may result in trauma or interruption of the middle tract (Hamilton et al., 1968). Division of the crista terminalis in dogs results in delayed atrial activation, division of the anterior and middle internodal tracts causes a delay in A-V conduction, while only the division of all three tracts may result in a nodal escape rhythm (Holsinger, Wallace, Young, and Sealy, 1966).

However, it seems unlikely that all tracts are injured during the Blalock-Hanlon operation (Hamilton et al., 1968). Injury to the sinus node or its blood supply has also to be taken into account as a possible cause for arrhythmias (Tung, James, Effler, and Mc Cormack, 1967). Of the 27 patients reported by Hamilton et al. (1968) nine (33\%) developed A-V junctional rhythm : this contrasts with the finding of Khoury et al. (1966) that only two (14\%) of 28 patients developed A-V junctional rhythm (which was the only kind of rhythm disturbance in their series).
In our study only 2 of the 64 patients presented with an ectopic atrial rhythm (or A-V junctional rhythm) following the Blalock-Hanlon procedure ; after fossa ovalis resection none of the patients developed A-V junctional rhythm; the supposition that a difference in the extent of surgical trauma may explain this different incidence remains unproved. $\mathbf{P}$-wave changes suggesting intraatrial block or left atrial enlargement were found in 11 patients $(18 \%)$ after the Blalock-Hanlon operation and in 8 patients (43\%) following fossa ovalis resection; Hamilton et al. (1968), and Khoury et al. (1966) reported an $18 \%$ and a $90 \%$ incidence respectively. The last authors attributed $\mathbf{P}$-wave changes to increased atrial work secondary to increased bidirectional shunting; the $\mathrm{P}$-wave changes of our two patient groups developed most frequently after 3 months, which makes surgical trauma an unlikely cause. The nature of the rhythm disturbances reported by Hamilton et al. is the same as in our series but the incidence of $59 \%$ contrasts with the low incidence in our series which does not differ significantly from the $14 \%$ reported by Khoury et al. A transient arrhythmia may be missed if the interval between the follow-up electrocardiograms is too long; this may in part explain the low incidence found by us and by Khoury et al. Serious disturbances of long duration proved to be rare in our study ; one patient died suddenly four weeks after fossa ovalis resection; the heart block was thought to have been caused by accidental surgical trauma by a suction cannula.

Following the Blalock-Hanlon operation five patients developed arrhythmias of longer duration, four of whom were in good clinical condition; only one patient with successively an atrial flutter and a supraventricular tachycardia was in severe heart failure, but later his condition improved, the electrocardiogram still showing an atrial tachycardia with $2: 1 \mathrm{~A}-\mathrm{V}$ conduction. Congestive heart failure may have been a contributing factor in causing arrhythmias in three patients having a $N$ transposition with ventricular septal defect in N which the Blalock-Hanlon procedure was com- N bined with a banding of the pulmonary artery. No correlation could be found between the incidence or the nature of the rhythm disturbances and the ages of the patients at the time of opera- $\mathbb{D}$ tion or the time of onset after operation; some of the disturbances occurred within two months after surgery and are possibly related to surgical $\underset{\mathbb{D}}{\mathbb{D}}$ trauma. However, this relation seems unlikely if $\stackrel{\mathcal{D}}{\mathbb{D}}$ a rhythm disturbance did not occur until some $\varrho$ years after operation. Digitalis cannot be excluded as a possible cause of arrhythmia, but in no case 
was a clear relationship between discontinuance of the drug and reversion to sinus rhythm suggested. Only one of our patients died with a rhythm disturbance (heart block) as a contributing factor; the postoperative electrocardiograms of the other patients who died showed no rhythm disturbances. For that reason it seems unlikely that arrhythmias contributed greatly to mortality in the patients in whom postoperative electrocardiograms were not available. Following balloon atrial septostomy no rhythm disturbances have been reported so far. It may be concluded from this study that serious arrhythmias following the surgical creation of an atrial septal defect are rare. In this respect no significant difference was found between the two surgical techniques used.

We should like to thank Professor Dr. A. G. Brom for permission to publish the data concerning the patients who underwent a Blalock-Hanlon operation.

\section{REFERENCES}

Blalock, A., and Hanlon, C. R. (1950). Surgical treatment of complete transposition of the aorta and the pulmonary artery. Surg. Gynec. Obstet., 90, 1.

Cornell, W. P., Maxwell, R. E., Haller, J. A., and Sabiston, D.C. (1966). Results of the Blalock-Hanlon operation in 90 patients with transposition of the great vessels. J. thorac. cardiovasc. Surg., 52, 525.
Hamilton, S. D., Bartley, T. D., Miller, R. H., Schiebler, G. L., and Marriot, H. J. L. (1968). Disturbances in atrial rhythm and conduction following the surgical creation of an atrial septal defect by the Blalock-Hanlon technique. Circulation, 38, 73.

Holsinger, J. W., Wallace, A. G., Young, W. G., and Sealy, W. C. (1966). Surgical significance of the specialized atrial internodal tracts. Surg. Forum, 17, 183.

Homan van der Heide, J. N., Eygelaar, A., Dorlas, J. C., and Bossina, K. K. (1967). Direct vision palliation of transposition on the great vessels. J. cardiovasc. Surg., 8, 292.

James, T. N. (1963). Connecting pathways between the sinus node and A-V node and between the right and the left atrium in the human heart. Amer. Heart J., 66, 498.

Khoury, G. H., Shaher, R. M., Fowler, R. S., and Keith, J. D. (1966). Preoperative and postoperative electrocardiogram in complete transposition of the great vessels. Amer. Heart J., 72, 199.

Litwin, S. B., Plauth, W. H., Jones, J. E., and Bernhard, W. F. (1971). Appraisal of surgical atrial septectomy for transposition of the great arteries. Circulation, Suppl. 1, $43,7$.

Nadas, A. S. (1963). Arrhythmias. In Paediatric Cardiology, 2nd ed., p. 226. Saunders, Philadelphia.

Paul, M. H., Van Praagh, S., and Van Praagh, R. (1968). Transposition of the great arteries. In Paediatric Cardiology, edited by H. Watson, pp. 576-610. LloydLuke, London.

Rashkind, W. J., and Miller, W. W. (1966). Creation of an atrial septal defect without thoractomy; palliative approach to complete transposition of the great arteries. J. Amer. med. Ass., 196, 991.

Tung, K. S. K., James, T. N., Effler, D. B., and Mc Cormack, L. J. (1967). Injury of the sinus node in open-heart operations. J. thorac. cardiovasc. Surg., 53, 814. 